\title{
Potential for the Use of the Solitaire Stent for Recanalization of Middle Cerebral Artery Occlusion without a Susceptibility Vessel Sign
}

\author{
Y.J. Bae, C. Jung, J.H. Kim, B.S. Choi, E. Kim, M.-K. Han, H.-J. Bae, and M.H. Han
}

\begin{abstract}
BACKGROUND AND PURPOSE: Absence of the MCA susceptibility vessel sign (negative MCA susceptibility vessel sign) on gradient recalled-echo MR imaging in acute stroke is commonly associated with in situ stenosis and thrombotic occlusion. We evaluated the effectiveness and safety of the Solitaire stent as the first-line device for the recanalization of MCA occlusion with a negative MCA susceptibility vessel sign.
\end{abstract}

MATERIALS AND METHODS: Thirty-eight consecutive patients presenting with acute ischemic stroke due to MCA occlusion were treated by using the Solitaire AB stent alone or combined with thrombolytic drugs. Among these patients, 11 ( 7 men and 4 women; median age, 70 years; range, 49-89 years) who underwent multimodal stroke MR imaging before the endovascular procedure and had no MCA susceptibility vessel sign on the initial gradient recalled-echo MR imaging were included in this study. The primary end point was the recanalization of the occluded artery evaluated by the arterial occlusive lesion score. Clinical outcome was assessed at discharge and 90 days, as was the degree of residual MCA stenosis or reocclusion.

RESULTS: Successful recanalization (arterial occlusive lesion score $\geq \mathrm{II}$ ) without balloon angioplasty was obtained in 9 patients (81.8\%). Six patients (54.5\%) had an mRS score of $\leq 2$ at 90 days. After a median of 147 days, no patient showed reocclusion on follow-up imaging. There were no symptomatic intracerebral hemorrhages.

CONCLUSIONS: The Solitaire stent is a feasible tool as the first-line device for multimodal endovascular recanalization therapy in acute ischemic stroke with a negative MCA susceptibility vessel sign. It has a good rate of successful and complete recanalization and is a fast yet safe procedure.

ABBREVIATIONS: GRE = gradient recalled-echo; SVS = susceptibility vessel sign

$\mathrm{T}$

he Solitaire stent (Covidien/ev3, Irvine, California) was initially developed as a device for assisting coil embolization of intracranial aneurysms. ${ }^{1-3}$ However, its ability to be completely and safely retrieved after full deployment allows it to be used as a device for mechanical thrombectomy in patients with acute thromboembolic stroke. Many reputable studies have shown that entrapping and extracting the thromboembolus by using the Solitaire stent is fast and effective in vascular recanalization, espe-

Received November 7, 2012; accepted after revision February 1, 2013.

From the Departments of Radiology (Y.J.B., C.J., J.H.K., B.S.C., E.K.) and Neurology (M.-K.H., H.-J.B.), Seoul National University Bundang Hospital, Gyeonggi-do, Republic of Korea; and Department of Radiology and Institute of Radiation Medicine (M.H.H.), Seoul National University College of Medicine, Seoul, Korea.

Paper previously presented at: 68th Korean Congress of Radiology, October 18-20, 2012; Seoul, Republic of Korea.

Please address correspondence to Cheolkyu Jung, MD, Department of Radiology, Seoul National University Bundang Hospital, 300, Gumi-dong, Bundang-gu, Seongnam-si, Gyeonggi-do, 463-787, Republic of Korea; e-mail: cheolkyu.jung. ni@gmail.com

http://dx.doi.org/10.3174/ajnr.A3562 cially when treating large arterial occlusions, including MCA occlusion. $^{4-8}$

Thromboembolus in the MCA is known to create the MCA susceptibility vessel sign (SVS) on gradient recalled-echo (GRE) MR imaging. ${ }^{9,10}$ This sign results from a T2-shortening effect of intracellular deoxyhemoglobin in the acute stage of a red blood cell clot. ${ }^{9}$ Thus, the MCA SVS is more commonly seen in red blood cell-dominant and mixed clots and can reflect the clot composition. ${ }^{9,11,12}$ Cho et $\mathrm{al}^{12}$ also showed that the SVS on GRE MR imaging was more commonly associated with cardioembolic stroke $(77.5 \%)$ than other stroke subtypes $(25.5 \%, P<.001)$. They suggested that the relatively greater thrombus burden in a cardioembolism may increase the conspicuity of SVS, so the SVS could be more frequently observed in cardioembolic stroke.

In contrast to the presence of the SVS, its absence is generally associated with a small amount of thrombus; fibrin-rich thrombus, a potential target for chemical thrombolysis; or an in situ steno-occlusive lesion, which could be an indication for angio- 
plasty. ${ }^{11,12}$ Consequently, we can assume that mechanical thrombectomy by using the Solitaire stent could be less effective in acute ischemic stroke with a negative MCA SVS, which could represent an in situ steno-occlusive lesion. To our knowledge, there has been no report demonstrating the effectiveness of the Solitaire stent in acute ischemic stroke with a negative MCA SVS. The purpose of our study was to evaluate the effectiveness and safety of mechanical thrombectomy by using the Solitaire stent in acute ischemic stroke with a negative MCA SVS.

\section{MATERIALS AND METHODS}

The institutional review board approved this retrospective study protocol and waived informed consent.

\section{Patients}

In our institution from September 2010 to March 2012, thirtyeight consecutive patients ( 21 men and 17 women; median age, 70 years; range, 49-89 years) presenting with acute ischemic stroke from an MCA occlusion were treated by using the Solitaire AB stent alone or combined with thrombolytic drugs. Among them, the patients who underwent multimodal MR imaging before the endovascular procedure and who had no MCA SVS on initial GRE MR imaging were included in our study.

The patients were divided into 3 different categories according to the interval change in their neurologic symptoms: "Fluctuating" symptoms indicated neurologic deficits that waxed and waned, "progressive" symptoms were defined as neurologic deficits that got worse as time passed, and "stable" symptoms referred to neurologic deficits that were maintained before the endovascular procedure.

\section{Stroke MR Imaging Protocol and Analysis}

MR imaging was performed by using a 1.5T or 3T unit (Gyroscan Intera; Philips, Best, the Netherlands) with a sensitivity encoding head coil. Patients underwent MR imaging by using the following routine stroke protocol in our institution before the endovascular procedure: DWI, TOF 3D angiography of the extracranial and intracranial arteries, GRE T2*-weighted imaging, MR perfusion, and gadolinium-enhanced T1- and T2-weighted FLAIR imaging. An average of 20 minutes was required for each routine stroke protocol MR imaging.

Acquisition parameters for GRE T2 ${ }^{\star}$-weighted images were set as follows: TR, 750-800 ms; TE, 10-15 msec; section thickness, 5 $\mathrm{mm}$; intersection gap, $1 \mathrm{~mm}$; FOV , $250 \times 250 \mathrm{~mm}$; flip angle, $20^{\circ}$.

All images were reviewed by 2 experienced neuroradiologists (B.S.C. and J.H.K.) who had 5 and 20 years of experience, respectively. If any discrepancy arose, the 2 readers analyzed images in consensus. First, the presence of the MCA SVS, defined as a hypointense signal change within the MCA with the diameter exceeding that of the contralateral vessel, was assessed on GRE MR imaging. ${ }^{9}$ The patients who had the MCA SVS were excluded from our study. Second, DWI-ASPECTS was estimated by the method of Barber et al. ${ }^{13}$

\section{Procedural Techniques}

All procedures were performed on a biplanar system (Integris Allura 12/12; Philips) by a single neurointerventionalist. Initial diagnostic cerebral angiography was performed via the transfemoral approach to identify the occluded MCA segment and to assess the collateral degree.

The proximal occluded segment of the MCA was defined on conventional angiography. ${ }^{14,15}$ The MCA trunk (M1) extends from the ICA bifurcation to the MCA trunk before secondary division. The MCA branches (M2) start from the secondary division. They course upward and over the insula and end at the top of the Sylvian fissure where they reach the apex of the circular sulcus. The MCA distal branches (M3 and M4) begin at the top of the circular sulcus and end at the surface of the lateral end of the Sylvian fissure.

A 6F balloon-guided catheter (Cello; Covidien/ev3 Neurovascular, Irvine, California; or Optimo; Tokai Medical Products, Aichi, Japan) was placed in the proximal cervical ICA. Then, a microcatheter (Prowler Select Plus; Codman Neurovascular, Miami Lakes, Florida; or Rebar 27; ev3) was advanced in the occluded vessel and navigated distal to the clot. Following this procedure, the Solitaire AB stent was advanced and deployed from a few millimeters distal to the clot. After immediate flow restoration was confirmed, the stent was kept deployed for approximately 3-10 minutes to ensure the entrapment of the clot. Afterward, the balloon guide was inflated and the microcatheter and stent were withdrawn gently, under the application of negative suction pressure, through the guiding catheter to prevent distal migration of the clot while retrieving the guide and microcatheter. When thrombectomy by using the Solitaire stent failed or partial recanalization was achieved, an intra-arterial thrombolytic agent (urokinase) was injected inside the clot. Intra-arterial and/or intravenous Aggrastat was infused during the procedure in selected patients who were without high risk of intracranial hemorrhage. The patients who had been under medication with anticoagulants or antithrombotics were not selected. Postprocedural cerebral angiography was performed to assess the recanalization status after the whole procedure.

\section{Outcome Assessment}

The degree of recanalization of the occluded MCA segment was evaluated with the arterial occlusive lesion score suggested by Khatri et al. ${ }^{16}$ Successful recanalization was defined as an arterial occlusive lesion score $\geq \mathrm{II}$, and complete recanalization, as an arterial occlusive lesion score of III.

On admission, clinical outcomes were assessed by 2 experienced neurologists (M.K.-H. and H.-J.B.) and their faculty. The $\mathrm{mRS}$ score for evaluation of the functional independence level was also recorded at discharge and 90 days after the procedure. A good clinical outcome was defined as an mRS score $\leq 2$ at discharge or at 90 days. On the patient's follow-up TOF MRA or CTA, the degree of residual MCA stenosis was determined. The degree of residual stenosis was graded according to the stenosis diameter as follows: normal $(0 \%)$, mild $(<50 \%)$, moderate $(50 \%-69 \%)$, severe $(\geq 70 \%)$, and occlusion (no visualization of the MCA segment distal to the occlusion). ${ }^{17}$

Complications associated with the procedure were also assessed. The major adverse events were the following: 1) deviceassociated complications, including arterial dissection, vessel perforation, or distal embolization; 2) procedural reocclusion of the 


\begin{tabular}{|c|c|c|c|c|c|c|c|c|c|c|c|c|c|c|c|}
\hline \multirow[b]{2}{*}{ Case } & \multirow[b]{2}{*}{ Sex } & \multirow[b]{2}{*}{$\begin{array}{l}\text { Age } \\
\text { (yr) }\end{array}$} & \multirow[b]{2}{*}{ Side } & \multirow[b]{2}{*}{$\begin{array}{c}\text { Occluded } \\
\text { Artery }\end{array}$} & \multirow{2}{*}{$\begin{array}{l}\text { Tandem } \\
\text { Stenosis }\end{array}$} & \multirow{2}{*}{$\begin{array}{l}\text { Other Extra- or } \\
\text { Intracranial } \\
\text { Atherosclerosis }^{\mathrm{a}}\end{array}$} & \multirow{2}{*}{$\begin{array}{c}\text { IV } \\
\text { rt-PA }\end{array}$} & \multirow[b]{2}{*}{$\begin{array}{l}\text { Add-On } \\
\text { Methods }\end{array}$} & \multirow[b]{2}{*}{$\begin{array}{c}\text { UK } \times \\
10^{3}\end{array}$} & \multirow[b]{2}{*}{ Tirofiban } & \multirow{2}{*}{$\begin{array}{l}\text { AOL } \\
\text { Score }\end{array}$} & \multirow{2}{*}{$\begin{array}{c}\text { Onset to } \\
\text { Puncture } \\
\text { (hr) }\end{array}$} & \multirow{2}{*}{$\begin{array}{l}\text { Recan. } \\
\text { Time } \\
\text { (min) }\end{array}$} & \multicolumn{2}{|c|}{ FU Artery Status } \\
\hline & & & & & & & & & & & & & & $\begin{array}{l}\text { First FU } \\
\text { (period) }\end{array}$ & $\begin{array}{l}\text { Last FU } \\
\text { (period) }\end{array}$ \\
\hline 1 & $F$ & 89 & $\mathrm{R}$ & Branch & Yes & Yes & Yes & IAT & 140 & IA & II & 3.6 & 103 & $\begin{array}{l}\text { Moderate } \\
\text { (1 day) }\end{array}$ & $\begin{array}{c}\text { Moderate } \\
\quad(4 \mathrm{mo})\end{array}$ \\
\hline 2 & M & 49 & L & Branch & No & Yes & Yes & IAT & 0 & $I A+I V$ & III & 50 & 11 & $\begin{array}{l}\text { Severe } \\
\text { (1 day) }\end{array}$ & $\begin{array}{l}\text { Severe } \\
\quad(12 \mathrm{mo})\end{array}$ \\
\hline 3 & $\mathrm{~F}$ & 85 & L & Trunk & No & Yes & No & IAT & 80 & IA & III & 17.5 & 38 & $\begin{array}{l}\text { Severe } \\
\text { (1 day) }\end{array}$ & $\begin{array}{l}\text { Severe } \\
\quad \text { ( } 5 \text { days })\end{array}$ \\
\hline 4 & M & 59 & L & Trunk & Yes & Yes & Yes & None & 0 & None & 0 & 15.2 & NA & $\begin{array}{l}\text { Occlusion } \\
\text { (6 days) }\end{array}$ & $\begin{array}{c}\text { Moderate } \\
\quad(5 \mathrm{mo})\end{array}$ \\
\hline 5 & M & 53 & $\mathrm{R}$ & Trunk & No & No & No & None & 0 & None & III & 12 & 25 & $\begin{array}{l}\text { Mild } \\
\text { (2 days) }\end{array}$ & $\begin{array}{l}\text { Mild } \\
\qquad(3 \mathrm{mo})\end{array}$ \\
\hline 6 & $\mathrm{~F}$ & 73 & $\mathrm{R}$ & Trunk & No & Yes & No & IAT & 80 & None & II & 14 & 45 & $\begin{array}{c}\text { Moderate } \\
\text { (1 day) }\end{array}$ & $\begin{array}{l}\text { Severe } \\
\quad(7 \mathrm{mo})\end{array}$ \\
\hline 7 & M & 49 & $\mathrm{R}$ & Trunk & No & No & No & IAT & 80 & None & I & 6.2 & NA & $\begin{array}{l}\text { Occlusion } \\
\text { (5 days) }\end{array}$ & NA \\
\hline 8 & M & 73 & $\mathrm{R}$ & Trunk & No & Yes & No & None & 0 & None & III & 9.1 & 27 & NA & NA \\
\hline 9 & M & 56 & $\mathrm{R}$ & Trunk & No & Yes & No & IAT, balloon & 60 & IV & III & 14.8 & 87 & $\begin{array}{l}\text { Severe } \\
\text { (1 day) }\end{array}$ & $\begin{array}{l}\text { Mild } \\
\text { (4 days) }\end{array}$ \\
\hline 10 & $\mathrm{~F}$ & 76 & L & Trunk & No & No & No & None & 0 & None & II & 21.7 & 42 & $\begin{array}{l}\text { Severe } \\
\quad \text { (4 days) }\end{array}$ & NA \\
\hline 11 & M & 70 & $\mathrm{R}$ & Trunk & No & Yes & No & None & 0 & None & III & 11 & 31 & $\begin{array}{l}\text { Severe } \\
\quad \text { (4 days) }\end{array}$ & NA \\
\hline
\end{tabular}

Note:- R indicates right; L, left; IAT, intra-arterial chemical thrombolysis; balloon, balloon angioplasty; IA, intra-arterial; UK, urokinase; AOL, arterial occlusive lesion; Recan. Time, time from puncture to recanalization; NA, not applicable; FU, follow-up.

${ }^{a}$ The presence of multifocal atherosclerosis at extra- or intracranial arteries.

intracranial artery; 3 ) symptomatic intracranial hemorrhage; and 4) death. Symptomatic intracranial hemorrhage was any hemorrhage demonstrated on the follow-up imaging leading to an interval decrease in the NIHSS score $\geq 4$ from baseline or the lowest NIHSS score between admission and 7 days or to death. ${ }^{18,19}$

\section{Statistical Analysis}

Continuous variables were expressed as the median value and range. Categoric variables were expressed as frequency by using percentages.

\section{RESULTS}

Of 38 patients with MCA occlusion, 11 (28.9\%) (7 men and 4 women; median age, 70 years; range, 49-89 years) were confirmed as having a negative MCA SVS. Among them, 5 (45.5\%) showed the onset of fluctuating symptoms, 3 (27.3\%) had progressive symptoms, and the remainder (27.3\%) had stable symptoms. The median DWI-ASPECTS calculated on the basis of initial MR imaging was 8 (range, 5-9).

All 11 patients had complete occlusion of 1 MCA segment on initial angiography. Nine of 11 patients $(81.8 \%)$ were confirmed to have an occlusion at the M1 segments. The remaining 2 patients (18.2\%) had occluded M2 segments. Tandem stenosis was noted in 2 patients (18.2\%): One patient had a left M1 occlusion with mild stenosis of the left proximal cervical ICA, and the other patient had a right $\mathrm{M} 2$ occlusion with mild stenosis of the right proximal cervical ICA.

Before the procedure, 2 of 11 patients (18.2\%) underwent intravenous thrombolysis with rtPA. The median time from symptom onset to puncture was 14 hours (range, 3.6-50.0 hours). As an add-on method, intra-arterial thrombolysis with urokinase was performed in 6 patients $(54.5 \%)$. One patient
(9.1\%) underwent additional balloon angioplasty for the occluded segment. Systemic or intra-arterial infusion of tirofiban was used in 4 patients $(36.4 \%)$ when the occluded artery was recanalized; 2 patients $(18.2 \%)$ received intra-arterial tirofiban loading and $1(9.1 \%)$ received intravenous loading. One patient $(9.1 \%)$ underwent intra-arterial tirofiban loading followed by intravenous maintenance. The overall clinical and procedural characteristics of the patients are shown in Tables 1 and 2.

\section{Procedural Outcome}

Of 11 patients with negative MCA SVS, successful and complete recanalization was obtained in $9(81.8 \%)$ and 6 patients $(54.5 \%)$, respectively. Successful and complete recanalization without balloon angioplasty was achieved in $72.7 \%$ and $45.5 \%$, respectively. After we excluded 2 patients with an arterial occlusive lesion score of 0 or I, the median time from puncture to recanalization was 38 minutes (range, 11-103 minutes).

\section{Clinical Outcome}

All patients were successfully followed for a median of 252 days (range, 113-547 days). Of 11 patients, $4(36.4 \%$ ) had an mRS $\leq 2$ at discharge and $6(54.5 \%)$ had an $\mathrm{mRS} \leq 2$ at 90 days.

\section{Patient Follow-Up}

The first follow-up CTA or MRA of patients with a negative MCA SVS was performed in 10 patients after a median of 1.5 days (range, 1-6 days) from arrival at the emergency department. The degree of residual MCA stenosis on the first follow-up imaging was mild in 1 patient $(9.1 \%)$, moderate in $2(18.2 \%)$, severe in 5 (45.5\%), and occlusion in $2(18.2 \%)$; all these features were pres- 
Table 2: Patient clinical features and clinical outcomes

\begin{tabular}{llccccccc}
\hline Case & $\begin{array}{c}\text { Symptom } \\
\text { Pattern }\end{array}$ & $\begin{array}{c}\text { DWI ASPECTS } \\
\text { Baseline }\end{array}$ & HT & sHT & $\begin{array}{c}\text { NIHSS } \\
\text { Baseline }\end{array}$ & $\begin{array}{c}\text { NIHSS } \\
\text { Discharge }\end{array}$ & $\begin{array}{c}\text { mRS } \\
\text { Discharge }\end{array}$ & $\begin{array}{c}\text { mRS at } \\
90 \text { Days }\end{array}$ \\
\hline 1 & Fluctuating & 8 & No & No & 20 & 10 & 4 & 4 \\
2 & Fluctuating & 9 & No & No & 3 & 2 & 2 & 1 \\
3 & Fluctuating & 7 & No & No & 17 & 4 & 4 & 3 \\
4 & Fluctuating & 6 & No & No & 17 & 15 & 5 & 3 \\
5 & Progressive & 5 & Yes & No & 6 & 1 & 1 & 1 \\
6 & Fluctuating & 7 & No & No & 6 & 6 & 3 & 2 \\
7 & Progressive & 8 & No & No & 7 & 8 & 4 & 3 \\
8 & Stable & 6 & No & No & 15 & 7 & 4 & 4 \\
9 & Stable & 8 & No & No & 15 & 2 & 1 & 1 \\
10 & Progressive & 8 & No & No & 7 & 8 & 4 & 2 \\
11 & Stable & 8 & No & No & 5 & 0 & 0 & 1 \\
\hline
\end{tabular}

Note:- - HT indicates hemorrhagic transformation; sHT, symptomatic hemorrhagic transformation.
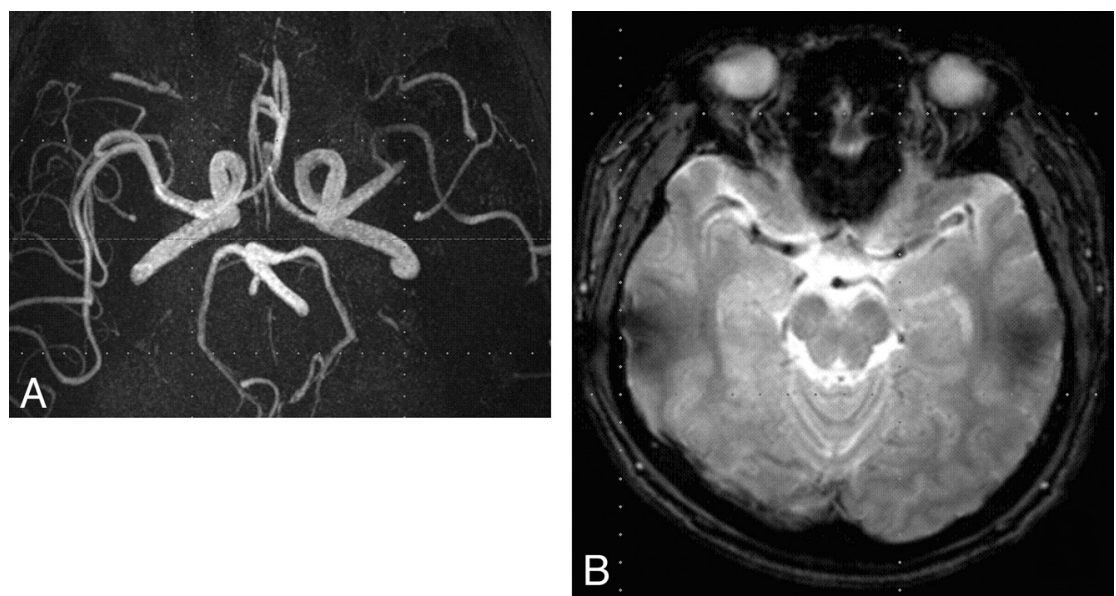

FIG 1. MR imaging in a 49-year-old man with acute ischemic stroke. A, MRA shows the occlusion of the superior division of the left MCA. B, On GRE MR imaging, the MCA SVS was absent.

ent on the initial baseline imaging. There was no case with reocclusion on the first follow-up imaging.

The second or last follow-up was after a median of 147 days (range, 25-367 days) in 7 of 11 patients (63.6\%); 4 patients did not have available follow-up imaging after the initial one. On the final follow-up imaging, mild residual stenosis was shown in 2 patients (18.2\%); moderate, in 2 patients (18.2\%); and severe, in another 3 patients $(27.3 \%)$. None of the cases showed reocclusion on the final follow-up imaging or symptom recurrence.

In 1 of 11 patients $(9.1 \%)$ (case 5) with right M1 occlusion, focal hemorrhage in the head portion of the right caudate nucleus was observed on the 3-hour follow-up CT after recanalization. However, no symptomatic hemorrhage was detected after the procedure. Procedural reocclusion occurred in 2 cases. Other than this, no complication, such as arterial dissection, vascular perforation, or distal embolism, developed in any patient. There was no procedure-related or other-cause mortality.

\section{Representative Case}

Case 2. A 49-year-old man visited the emergency department of our institution with fluctuating motor aphasia and dysarthria. Symptom onset time was 2 days before the hospital visit, and his initial NIHSS score was 3. The patient underwent MR imaging with a stroke protocol, and an occlusion of the left M2 segment of the MCA with multiple small infarctions in the left basal ganglia and subcortical white matter was confirmed (Fig $1 A$ ). The DWI-ASPECTS was 9. No initial MCA SVS was demonstrated (Fig 1B).

Because his symptoms worsened to an NIHSS score of 13 immediately after the MR imaging, intravenous rtPA infusion was initiated, and endovascular recanalization therapy for the left M2 occlusion was performed. The occlusion of the left M2 segment was also confirmed by conventional angiography (Fig $2 A$ ). Immediate flow restoration of the occluded segment was achieved by temporary Solitaire stent deployment in the occluded segment for 5 minutes (Fig $2 B$ ). After the Solitaire stent was removed, in situ moderate stenosis of the occluded segment was identified by postprocedural angiography (Fig 2C). Therefore, an additional intra-arterial loading of $500 \mathrm{mcg}$ of tirofiban was performed manually, followed by intravenous maintenance. Mechanical recanalization alone took approximately 11 minutes, and the entire intra-arterial thrombolysis procedure took approximately 38 minutes.

\section{DISCUSSION}

To date, the Solitaire stent has been known to be effective for flow restoration in acute ischemic stroke, especially for mechanical thrombectomy in an acute occlusion of the large intracranial artery. ${ }^{4-8,20,21}$ However, it is unknown whether the Solitaire stent could be used as a thrombectomy device and could be effective in recanalizing an in situ steno-occlusive lesion. In this study, we performed multimodal endovascular recanalization therapy by using the Solitaire stent as a first-line device for 38 MCA occlusions, and 11 MCA occlusions (28.9\%) were verified as not showing the MCA SVS on GRE MR imaging. The rate of negative MCA SVS was in accordance with a previous report. ${ }^{9}$ Among these $11 \mathrm{MCA}$ occlusions with negative MCA SVS, successful recanalization without balloon angioplasty was achieved in $72.7 \%$ of the patients, with a median recanalization time of 38 minutes (range, 11-103 minutes). Several case series describing thrombectomy by using the Solitaire stent have reported successful recanalization, with a success rate between $62 \%$ and $100 \% \cdot{ }^{4-8,20,21}$ However, the first multicenter, prospective, randomized trial for the Solitaire system (the Solitaire With the Intention For Thrombectomy [SWIFT] trial) showed that successful recanalization (Thrombolysis in Myocardial Infarction grade 2 or 3) without symptomatic intracranial hemorrhage was achieved in $61 \%$ of the Solitaire group. ${ }^{8}$ Thus, our results do not appear to be worse than those of the SWIFT trial. This finding suggests the possibility that Solitaire thrombectomy, with or without chemical thrombolysis, could result in successful, rapid, and safe arterial 

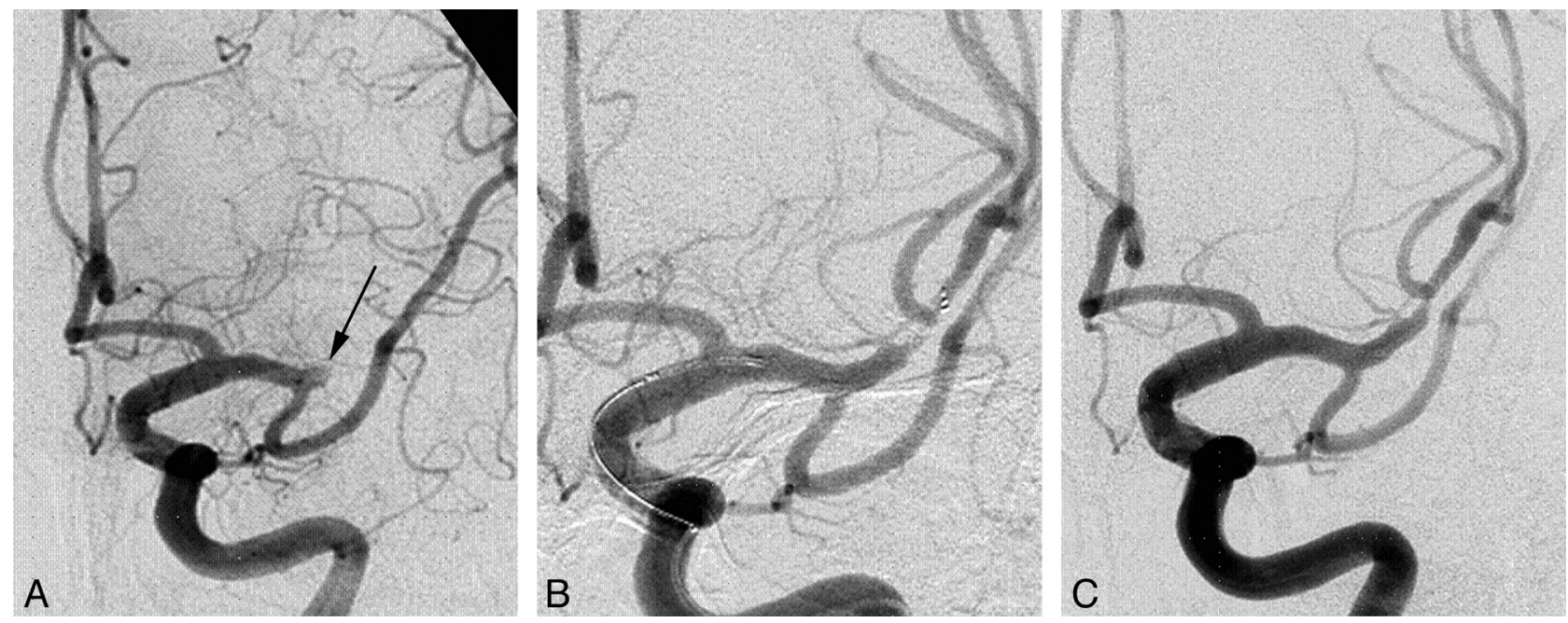

FIG 2. A, Initial conventional angiography shows complete occlusion of the left $M 2$ segment of the MCA (arrow). B, Conventional angiography shows immediate blood flow restoration achieved by Solitaire stent deployment. C, After mechanical thrombectomy, moderate stenosis is noted at the occlusion site.

recanalization with balloon angioplasty or permanent stent placement, even in cases without the MCA SVS.

Some case series have shown that an in situ steno-occlusive lesion is related to incomplete vessel recanalization and may require additional balloon angioplasty or permanent stent placement. ${ }^{22}$ Balloon angioplasty with or without stent placement as a first-line method could have some disadvantage in the setting of hyperacute or acute ischemic stroke. First, the rate of adverse events could be higher without antithrombotic premedication, partly due to plaque vulnerability. ${ }^{23-25}$ Dorn et a ${ }^{25}$ reported that the rate of adverse events was $87.5 \%$ for acute stroke with complete occlusion but $8.3 \%$ for a scheduled angioplasty procedure. Second, anatomic factors such as vessel tortuosity, occlusion length, or diameter of the proximal or distal portion of occlusion, as well as the neurointerventionalist's experience, could be critical for the technical success and procedural outcome of balloon angioplasty. ${ }^{26}$ Finally, whether aggressive medical therapy or angioplasty with or without stent placement in combination with aggressive medical therapy is the better treatment method for symptomatic intracranial stenosis is still under debate. ${ }^{26,27}$ Consequently, we considered that balloon angioplasty with or without stent placement was the second option for acute ischemic stroke without the SVS.

The theoretic background for this interesting result could be found in studies of the relationship of atherosclerotic plaque and thrombus formation. ${ }^{28,29}$ Arterial atherosclerotic plaques can induce intraluminal thrombus formation at the site of maximal stenosis or just distal to it. This phenomenon, known as "atherothrombosis," is due to the advanced lipid core of the atherosclerotic plaque, which is rich in tissue factors that activate platelets and promote coagulation if released into the blood by either rupture or ulceration of the plaque. ${ }^{30}$ Thus, vulnerable plaques with intra-arterial thrombus may act as the cause of acute ischemic stroke with in situ stenosis rather than hemodynamic instability. ${ }^{26,28}$ Because the MCA SVS reflects clot composition and burden, the atherothrombus may exist without demonstrating the MCA SVS on GRE MR imaging because of a different clot composition or a small amount of clotting. ${ }^{11,12}$ Moreover, even in the vessel showing MCA SVS, a concurrent atherothrombus with in situ atherosclerotic stenosis may be present. Therefore, considering the possibility of an underlying atherothrombus in the stenotic artery, we can conclude that mechanical thrombectomy by using the Solitaire stent could be effective, even in acute ischemic stroke without the MCA SVS, by removing the thrombus within stenotic lesion.

Rapid arterial rethrombosis is associated with high-grade residual stenosis and usually occurs at the site of the initial occlusion, resulting in reocclusion of the recanalized artery. ${ }^{31}$ Because platelet activation is a key step in thromboembolism in the reocclusion of an in situ steno-occlusive lesion, ${ }^{31-34}$ intravenous or intra-arterial glycoprotein IIb/IIIa inhibitors could be effective for preventing reocclusion. ${ }^{32,34}$ On the basis of the findings of the Abciximab in Emergency Treatment of Stroke Trial, which showed an increased rate of symptomatic or fatal intracranial hemorrhage, ${ }^{35}$ we used intravenous or intra-arterial tirofiban in our study only when no contraindication existed.

Another interesting finding was that the percentage of patients who demonstrated fluctuating symptoms was relatively high in our study. Several reports have suggested that fluctuating symptoms might be a manifestation of intracranial vascular occlusion with marginal blood flow supplied by collateral circulation. ${ }^{36}$ In particular, fluctuating symptoms may suggest existing but unstable and insufficient collateralization, ${ }^{37}$ which means that intervention including thrombolytic therapy should be considered for patients with this pattern of symptoms. We thought that fluctuating symptoms could be one of the surrogate markers to predict in situ stenosis as the cause of the occlusion.

There are a few limitations to our study. First, this was a preliminary report including only a small number of patients. Second, for this retrospective study, we chose consecutive patients who underwent endovascular intervention with the Solitaire stent due to acute neurologic deficits caused by MCA occlusion. This choice led to an unavoidable selection bias. Third, the high section thickness of the GRE sequence $(5 \mathrm{~mm})$ could 
give false-negative results regarding the MCA SVS. Third, the follow-up imaging technique and the interval between each follow-up was not consistent among the patients. The precise comparison of the degree of vessel stenosis is not possible. Therefore, a large randomized prospective study needs to be performed, and the effectiveness of the Solitaire stent should be proved with statistical analysis.

\section{CONCLUSIONS}

The Solitaire stent is a feasible tool as a first-line device for endovascular intervention in acute ischemic stroke without the MCA SVS. It not only provides a good rate of successful and complete recanalization but also enables rapid yet safe vascular recanalization without reported complications. The most likely theory for its function is that the removal of the atherothrombus by Solitaire thrombectomy results in arterial recanalization, but the exact pathologic mechanism is still unclear. To confirm this theory, further prospective studies with long-term follow-up should be conducted.

Disclosures: Hee-Joon Bae-UNRELATED: Board Membership: Bayer Korea, Boehringer Ingelheim Korea, Bristol-Myers Squibb Korea, MSD Korea, Novartis Korea, Consultancy: YuYu Pharmaceutical Co, Grants/Grants Pending: ESAl-Korea, ${ }^{*}$ SanofiAventis Korea, ${ }^{*}$ Bayer-Korea, ${ }^{*}$ Ostuka Korea, ${ }^{*}$ Pfizer Inc, ${ }^{*}$ Dae Woong Pharmaceutical Co, ${ }^{*}$ Daichi Sankyo, ${ }^{*}$ Yuhan Corporation, ${ }^{*}$ Dong-A Pharmaceutical Co, Payment for Lectures (including service on Speakers Bureaus): Bayer Korea, AstraZeneca Korea, MSD Korea, Bristol-Myers Squibb Korea, Novatis Korea, Ostuka Korea, Pfizer Korea, Daichi Sankyo Korea, Handok Pharmaceuticals Co, Payment for Manuscript Preparation: Bayer Korea, Ostuka Korea. Moon Hee Han-UNRELATED: Consultancy: MicroVention. * ${ }^{*}$ Money paid to the institution.

\section{REFERENCES}

1. Henkes H, Flesser A, Brew S, et al. A novel microcatheter-delivered, highly-flexible and fully-retrievable stent, specifically designed for intracranial use. Interv Neuroradiol 2003;9:391-93

2. Lubicz B, Collignon L, Raphaeli G, et al. Solitaire stent for endovascular treatment of intracranial aneurysms: immediate and midterm results in 15 patients with 17 aneurysms. J Neuroradiol 2010;37:83-88

3. Klisch J, Eger C, Sychra V, et al. Stent-assisted coil embolization of posterior circulation aneurysms using Solitaire ab: preliminary experience. Neurosurgery 2009;65:258

4. Castaño C, Dorado L, Guerrero C, et al. Mechanical thrombectomy with the Solitaire AB device in large artery occlusions of the anterior circulation: a pilot study. Stroke 2010;41:1836-40

5. Stampfl S, Hartmann M, Ringleb PA, et al. Stent placement for flow restoration in acute ischemic stroke: a single-center experience with the Solitaire stent system. AJNR Am J Neuroradiol 2011;32:1245-48

6. Brekenfeld C, Schroth G, Mordasini P, et al. Impact of retrievable stents on acute ischemic stroke treatment. AJNR Am J Neuroradiol 2011;32:1269-73

7. Nayak S, Ladurner G, Killer M. Treatment of acute middle cerebral artery occlusion with a Solitaire $\mathrm{AB}$ stent: preliminary experience. Br J Radiol 2010;83:1017-22

8. Saver JL, Jahan R, Levy EI, et al, for the SWIFT Trialists. Solitaire flow restoration device versus the Merci retriever in patients with acute ischaemic stroke (SWIFT): a randomised, parallel-group, non-inferiority trial. Lancet 2012;380:1241-49

9. Rovira A, Orellana P, Alvarez-Sabín J, et al. Hyperacute ischemic stroke: middle cerebral artery susceptibility sign at echo-planar gradient-echo MR imaging. Radiology 2004;232:466-73

10. Flacke S, Urbach H, Keller E, et al. Middle cerebral artery (MCA) susceptibility sign at susceptibility-based perfusion MR imaging: clinical importance and comparison with hyperdense MCA sign at CT. Radiology 2000;215:476-82

11. Liebeskind DS, Sanossian N, Yong WH, et al. CT and MRI early vessel signs reflect clot composition in acute stroke. Stroke 2011;42:1237-43

12. Cho KH, Kim JS, Kwon SU, et al. Significance of susceptibility vessel sign on $\mathrm{T} 2{ }^{*}$-weighted gradient echo imaging for identification of stroke subtypes. Stroke 2005;36:2379-83

13. Barber PA, Hill MD, Eliaziw M, et al. Imaging of the brain in acute ischaemic stroke: comparison of computed tomography and magnetic resonance diffusion-weighted imaging. J Neurol Neurosurg Psychiatry 2005;76:1528-33

14. Smith WS, Sung G, Starkman S, et al. Safety and efficacy of mechanical embolectomy in acute ischemic stroke: results of the MERCI trial. Stroke 2005;36:1432-38

15. Fiehler J, Knudsen K, Thomalla G, et al. Vascular occlusion sites determine differences in lesion growth from early apparent diffusion coefficient lesion to final infarct. AJNR Am J Neuroradiol 2005;26:1056-61

16. Khatri P, Neff J, Broderick JP, et al. Revascularization end points in stroke interventional trials: recanalization versus reperfusion in IMS-I. Stroke 2005;36:2400-03

17. Wong K, Lam WWM, Liang E, et al. Variability of magnetic resonance angiography and computed tomography angiography in grading middle cerebral artery stenosis. Stroke 1996;27:1084-87

18. Wahlgren N, Ahmed N, Davalos A, et al. Thrombolysis with alteplase for acute ischaemic stroke in the Safe Implementation of Thrombolysis in Stroke-Monitoring Study (SITS-MOST): an observational study. Lancet 2007;369:275-82

19. Larrue V, von Kummer R, Müller A, et al. Risk factors for severe hemorrhagic transformation in ischemic stroke patients treated with recombinant tissue plasminogen activator: a secondary analysis of the European-Australasian Acute Stroke Study (ECASS II). Stroke 2001;32:438-41

20. Miteff F, Faulder K, Goh A, et al. Mechanical thrombectomy with a self-expanding retrievable intracranial stent (Solitaire $\mathrm{AB}$ ): experience in 26 patients with acute cerebral artery occlusion. AJNR Am J Neuroradiol 2011;32:1078-81

21. Costalat V, Machi P, Lobotesis K, et al. Rescue, combined, and standalone thrombectomy in the management of large vessel occlusion stroke using the Solitaire device: a prospective 50-patient singlecenter study. Stroke 2011;42:1929-35

22. Ueda T, Sakaki S, Nochide I, et al. Angioplasty after intra-arterial thrombolysis for acute occlusion of intracranial arteries. Stroke 1998;29:2568-74

23. Suh DC, Kim JK, Choi JW, et al. Intracranial stenting of severe symptomatic intracranial stenosis: results of 100 consecutive patients. AJNR Am J Neuroradiol 2008;29:781-85

24. Suh DC, Kim EH. The therapeutic time window related to the presenting symptom pattern, that is, stable versus unstable patients, can affect the adverse event rate of intracranial stenting. Stroke 2009;40:e588-89, author reply e590

25. Dorn F, Prothmann S, Wunderlich S, et al. Stent angioplasty of intracranial stenosis: single center experience of 54 cases. Clin Neuroradiol 2012;22:149-56

26. Abou-Chebl A, Steinmetz H. Critique of "Stenting versus aggressive medical therapy for intracranial arterial stenosis" by Chimowitz, et al in the New England Journal of Medicine. Stroke 2012;43:616-20

27. Chimowitz MI, Lynn MJ, Derdeyn CP, et al. Stenting versus aggressive medical therapy for intracranial arterial stenosis. N Engl J Med 2011;365:993-1003

28. Ogata J, Masuda J, Yutani C, et al. Mechanisms of cerebral artery thrombosis: a histopathological analysis on eight necropsy cases. J Neurol Neurosurg Psychiatry 1994;57:17-21

29. Komotar RJ, Mocco J, Wilson DA, et al. The natural history of intracranial carotid artery atherosclerosis. Neurosurg Focus 2005;18:e5 
30. Rauch U, Osende JI, Fuster V, et al. Thrombus formation on atherosclerotic plaques: pathogenesis and clinical consequences. Ann Intern Med 2001;134:224

31. Heo JH, Lee KY, Kim SH, et al. Immediate reocclusion following a successful thrombolysis in acute stroke: a pilot study. Neurology 2003;60:1684-87

32. Mangiafico S, Cellerini M, Nencini $P$, et al. Intravenous glycoprotein IIb/IIIa inhibitor (tirofiban) followed by intra-arterial urokinase and mechanical thrombolysis in stroke. AJNR Am J Neuroradiol 2005;26:2595-601

33. Torgano G, Zecca B, Monzani V, et al. Effect of intravenous tirofiban and aspirin in reducing short-term and long-term neurologic deficit in patients with ischemic stroke: a double-blind randomized trial. Cerebrovasc Dis 2010;29:275-81
34. Kwon JH, Shin SH, Weon YC, et al. Intra-arterial adjuvant tirofiban after unsuccessful intra-arterial thrombolysis of acute ischemic stroke: preliminary experience in 16 patients. Neuroradiology 2011;53:779-85

35. Adams HP Jr, Effron MB, Torner J, et al. Emergency administration of abciximab for treatment of patients with acute ischemic stroke: results of an international phase III trial: Abciximab in Emergency Treatment of Stroke Trial (AbESTT-II). Stroke 2008;39:87-99

36. Johnston DC, Hill MD. The patient with transient cerebral ischemia: a golden opportunity for stroke prevention. CMAJ 2004; 170:1134-37

37. Jakubowska MM, Michels P, Müller-Jensen A, et al. Endovascular treatment in proximal and intracranial carotid occlusion 9 hours after symptom onset. Neuroradiology 2008;50:599-604 